\title{
A review of parenting and adolescent sexual behavior: The moderating role of gender
}

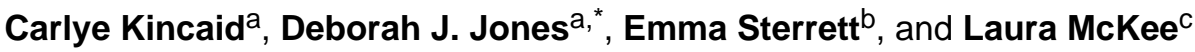 \\ aDepartment of Psychology, University of North Carolina at Chapel Hill, Chapel Hill, NC, USA \\ ${ }^{b}$ Department of Psychology, Clark University, Worcester, MA, USA \\ 'Department of Psychology, University of Louisville, Louisville, KY, USA
}

\begin{abstract}
In spite of the established link between parenting and adolescent sexual risk behavior, less is known about the role of adolescent gender as a potential moderator of this association. This literature review integrates findings from 24 studies to examine gender as a moderator of the link between parenting and youth sexual risk behavior. Despite the wide variability in methodology across the reviewed studies, findings suggest that monitoring may be more protective against sexual risk behavior for boys than girls, whereas parental warmth and emotional connection may be an especially salient factor for girls. The results of this review support further research on gender as an important factor in better understanding the role of parenting in the development of adolescent sexual behavior. Furthermore, the findings highlight the potential role of genderspecific, tailored family-focused prevention programs targeting sexual behavior.
\end{abstract}

\section{Keywords}

Gender; Sexual risk behavior; Parenting; Adolescent; Adolescence

\section{Introduction}

Sexual risk behavior among youth, defined as early sexual initiation, unprotected intercourse, or sex with multiple partners, is a major area of concern given the many associated negative consequences (Center for Disease Control \& Prevention, 2008); however, parental influence is one of the primary protective factors for at-risk adolescents (Kotchick, Shaffer, \& Forehand, 2001; Zimmer-Gembeck \& Helfand, 2008). Although the link between parenting and adolescent sexual risk behavior is well established, much less attention has been given to understanding the moderating role of adolescent gender. Within this review, the term gender will be utilized. The purpose of this literature review is to determine whether gender moderates the relation between parenting and adolescent sexual risk behavior. As more programs target the prevention of adolescent sexual behavior within the family context (Brody et al., 2006; DiClemente et al., 2008; Dittus, Miller, Kotchick, \& Forehand, 2004), a thorough understanding of the moderating role of gender has the potential to guide prevention program development and implementation. 


\subsection{Adolescent sexual behavior and consequences}

In recent years, researchers have increasingly turned their attention to the risks and problems associated with adolescent sexual behavior (Zimmer-Gembeck \& Helfand, 2008). Within this paper, the term "adolescence" refers to an age span between 10 and 18 years, encompassing early and middle adolescence (Baumrind, 1991a; Zimmer-Gembeck \& Helfand, 2008). Late adolescence typically extends from high school to young adulthood; however, this period of development is not as relevant to the current review, given the late adolescent's greater separation from parental authority.

The most recent survey of adolescent sexual behavior indicates that nearly $50 \%$ of youth (grades 9-12) in the United States are sexually active (CDC, 2008). Among sexually active youth, $7.1 \%$ initiated sexual intercourse before 13 years of age (i.e., early adolescence), $14.9 \%$ had sexual intercourse with four or more partners, and over one third (38.5\%) had not used a condom during their last sexual intercourse (CDC, 2008). Sexual behaviors such as early sexual initiation, unprotected intercourse, and sex with multiple partners put youth at risk for a range of negative consequences, such as unplanned pregnancy and sexually transmitted infections (STIs), including the human immunodeficiency virus (HIV). Currently, there are an estimated 9.1 million cases of sexually transmitted infections (STIs) among young persons ages 15-24 (CDC, 2008). Given the significance of this period in regard to sexual development and risk behavior, it is of critical importance to understand the risk and resilience-promoting factors associate with youth sexual behavior.

\subsection{Competing perspectives: how 'risky' is sexual behavior during adolescence?}

There is some debate over whether youth sexual behavior is best conceptualized as "risky deviance" or a "positive developmental task" (Zimmer-Gembeck \& Helfand, 2008). From the latter perspective, youth sexual behavior is viewed as part of normal development. Unlike delinquent behavior, youth sexual behavior has been described by some as a normative adolescent activity that almost every individual will engage in by young adulthood. From a biopsychosocial model (Smith, Udry, \& Morris, 1985; Udry, 1988), researchers emphasize that the normative biological (e.g., hormones, physical maturation) and relational (e.g., dating) aspects of sexuality promote the onset and patterns of sexual behavior during adolescence.

Alternatively, others emphasize several biological, social and psychological mechanisms that increase the level of risk associated with sexual behavior during this period. Although the formation of a sexual identity is a normative developmental milestone (Siqueira \& Diaz, 2004), it is also true that the establishment of a sexual identity does not depend on the initiation of sexual activity during adolescence. From a neurobiological perspective, adolescence is a unique developmental period during which the structures comprising the socio-emotional network (e.g., subcortical regions including the amygdala and ventral stratum) are developing rapidly whereas the structures comprising the cognitive control network (e.g., the prefrontal cortex) are slower to mature (Somerville, Jones, \& Casey, 2010). The accelerated development of the socio-emotional network, therefore, leads to a heightened responsiveness to emotional cues (e.g., sexual attraction) while the capacity to engage in cognitive and emotional regulation is still relatively immature (Somerville et al., 2010). The prefrontal cortex, the area of the brain responsible for decision-making, reasoning and planning, is the last area of the brain to develop and does not reach full maturation until early adulthood. As a result, the youth cognitive control network is less effective at imposing regulatory control over impulsive and risky behavior during the heightened states of arousal (Steinberg, 2008). 
The combination of increased sensitivity to emotional and social stimuli (e.g., accelerated reactivity to physical attraction, etc.) and immature cognitive control heightens the propensity for sexual behavior during adolescence. Somerville et al. (2010) maintain that adolescents display a "functionally imbalanced pattern of neural activity that may be related to behavioral deficits in successfully inhibiting emotional responses" (p. 129). Furthermore, adolescents' emotion regulation skills are disproportionately developed in comparison to their enhanced sensitivity to social and emotional cues. Accordingly, adolescents are far less equipped than adults to deal with the complex emotional processes that are often associated with relationship intimacy and sexual intercourse (Rose et al., 2005).

In adolescence, many young persons are still developing a stable sense of self and a repertoire of coping strategies to deal with the often-intense emotions that accompany the positive and negative aspects of sexual intimacy. In one study utilizing retrospective reports to examine adolescents' attitudes toward early sexual encounters, younger adolescents (ages 12-14) were more likely to report that they wish they had waited to have sexual intercourse (Brown \& Flanigan, 2003). For many, sexual behavior at an early age can take a serious toll on both psychological and physiological well-being.

Whereas normative adolescent development is characterized by the aforementioned vulnerabilities in regard to sexual risk behavior, there are also theories that explain sexual risk behavior as a marker of adolescent deviancy more broadly, clustering with other delinquent behaviors. Problem Behavior Theory (Jessor \& Jessor, 1977; Jessor, Van Den Bos, Vanderryn, Costa, \& Turbin, 1995), for example, emphasizes unconventional attitudes, traits and social bonds as precursors of deviant behaviors, including sexual risk behavior (Costa, Jessor, Donovan, \& Fortenberry, 1995). According to this perspective, the likelihood of sexual intercourse is greater among youth who are lacking in social bonds and may have unconventional dispositions. As Zimmer-Gembeck and Helfand (2008) suggest in their review of adolescent sexual behavior, there may be multiple pathways that are associated with sexual intercourse in adolescence, ranging on a spectrum of behaviors that reflect "risky deviance" or "normative development." Nonetheless, the multiple risks associated with sexual behavior in adolescence cannot be understated. Given the vulnerabilities and consequences associated with adolescent sexual behavior, there is a clear need to elucidate the antecedents and correlates as well as moderators of these associations.

\subsection{Parenting and adolescent sexual risk behavior}

Several theoretical models of human development recognize the influence of caregivers as agents of emotional, cognitive and relational socialization for offspring (Bronfenbrenner, 1979; Super \& Harkness, 1999). Bronfenbrenner's seminal model places parents within the microsystem, or the innermost circle of influence. Parents exert influence on the child directly via shared genetics, parenting style, and parenting behaviors. Super and Harkness (1999) also emphasize parents as powerful regulators of the subsystems surrounding the child, both directly and indirectly.

Baumrind's $(1978,1991 b)$ work emphasizes the major ways in which parenting directly contributes to child behaviors. Authoritative parenting style (Baumrind, 1978) is characterized by a balance of warmth/support and monitoring/control and has been linked to optimal child outcomes in European American and African American youth (e.g., McMahon \& Forehand, 2003; Jones et al., 2005; Sterrett, Jones, \& Kincaid, 2009). A burgeoning literature has examined the role of the specific parenting behaviors that characterize an authoritative parenting style: behavioral control/monitoring, psychological control, and warmth/support (Buhi \& Goodson, 2007; Kincaid, Jones, Cuellar, \& Gonzalez, 2011; Miller, Benson, \& Galbraith, 2001); below, the relationship between each parenting construct and adolescent sexual risk behavior will be discussed. 
Behavioral control is the parenting construct most commonly studied in relation to adolescent sexual risk behavior (Buhi \& Goodson, 2007). Parental monitoring (a commonlyused indirect measure of behavioral control) includes knowledge of youth where-abouts, as well as oversight of youth activities (Stattin \& Kerr, 2000). Monitoring affects sexual activity by restricting adolescent opportunities to engage in risk behaviors (Sieverding, Adler, Witt, \& Ellen, 2005). The association between higher levels of behavioral control/ knowledge about children's whereabouts (e.g., monitoring) and lower levels of adolescent risk behavior has been well-documented in the literature, including among diverse socioeconomic and ethnic groups (Li, Feigelman, \& Stanton, 2000; Li, Stanton, \& Feigelman, 2000; Rai et al., 2003).

In addition to behavioral control, Barber (2002) further differentiated psychological control as a psychologically-oriented, intrusive and manipulative form of parental control in which parents appear to maintain their own status at the expense of the child's autonomy by means of guilt induction, love withdrawal, and excessive criticism. By exercising control over the psychological world of the adolescent, parents inhibit the development of mature decisionmaking skills and appraisal of the self as a competent, self-governing agent (Cummings, Davies, \& Campbell, 2000); subsequently, these deficits are thought to increase vulnerability to sexual risk behavior by damaging the adolescent's sense of self-competency and relationship stability (Kincaid et al., 2011).

Beyond the domains of behavioral and psychological control, parental warmth and support also hold important implications for adolescent development (Masten \& Coatsworth, 1998). Support refers to parental behaviors toward the child, such as praising, hugging and encouraging, indicating that the child matters to the parent (Rollins \& Thomas, 1979). Parental warmth and support are associated with a range of positive adolescent outcomes (Masten \& Coatsworth, 1998), whereas a lack of support is often linked to a range of problem behaviors, including sexual risk behavior (Baumrind, 1991b). In regard to sexual behavior among adolescents, positive relationships characterized by high levels of warmth and support may act as a conduit through which parents impart their views or morals and help guide youth in decision making skills, affecting their involvement in risk behavior (Coley, Votruba-Drzal, \& Schindler, 2009; Sieverding et al., 2005).

Parents play a pivotal role in acting as social control and attachment models for their adolescents by providing emotional connections, behavioral constraints and modeling of relationship processes. Adolescence is a time when individuals often begin to explore and navigate romantic and intimate relationships with others. Accordingly, they often draw on the cognitive, emotional and behavioral aspects of the parent-child context as examples of self-regulation, emotional expression, and expectancies regarding behaviors and relationships (Gray \& Steinberg, 1999; Hawkins \& Weis, 1985). When parents provide warmth/support, appropriately monitor behavior, and practice discipline in non-coercive ways, adolescents are more likely to develop interpersonal security and observe boundaries that shape involvement in sexual activity (Longmore, Manning, \& Giordano, 2001).

\subsection{Examining the role of gender}

In spite of the established link between parenting and youth sexual risk behavior (e.g., Baumrind, 1978; DiClemente et al., 2008; Kotchick et al., 2001), less is known about the role of adolescent gender as a potential moderator of this association. Although there are many variables that likely interact with parenting and adolescent sexual behavior, as well as with adolescent gender (e.g., ethnicity, neighborhood, youth age, etc.; see Zimmer-Gembeck $\&$ Helfand, 2008, for a review of other noteworthy correlates), there are two primary reasons for our specific focus on gender in the current review. First, relatively few studies in the parenting and adolescent sexual behavior literature examine the role of adolescent gender, 
let alone gender and other moderating variables, such as those named above. At this time, there are too few studies to conduct a quantitative investigation to better disentangle this issue (Berman \& Parker, 2002); however, more attention to gender in future work will provide the opportunity to conduct a meta-analysis of findings. Accordingly, we would be citing individual studies in many cases (if any studies at all in others), rather than presenting a review across studies. Second, we believe that an examination of gender as a moderator of the link between parenting and adolescent sexual behavior is a critical first step in the advancement of this literature and, in turn, tailored prevention and intervention programming.

Although previous literature on adolescent sexual behavior gave occasional mention to the role of warmth and relationship quality, the majority of earlier research on parenting emphasized the development of moral values, particularly among young boys (Fagot, 1995). Bronfenbrenner $(1961,1979)$ was among the first to suggest that parenting behaviors, including parental affection and tenable authority, may have differential effects on boys and girls. Baumrind and Black (1967) reported that girls were often highly competent in conditions of low structure and high warmth, whereas boys were less likely to thrive in such environments. Similarly, Hoffman (1991) argued that boys and girls may respond differently to different types of parenting due to their unique genetic constitutions and temperaments, which may then shape future parenting behaviors as a result (e.g., Sameroff, 1975).

Resilience-promoting socialization processes and child-rearing environments may differ for boys and girls (Mash \& Barkley, 2003), particularly in regard to the onset and maintenance of sexual risk taking. Hops (1995) suggests that the pathways from childhood to adolescence and adult pathology are age and gender specific and these differences may be the result of different social contexts for males and females. For example, resilience in boys has been associated with households where there is a male role model, greater structure, and more rules (i.e., the latter two are correlates of more consistent monitoring practices), whereas resilient girls tend to come from households that foster independence within the adolescent while simultaneously providing quality support from a female caregiver (Mash \& Barkley, 2003; Werner, 1995).

Although the findings on gender differences are complex, the extant literature strongly suggests that the role of gender is critical to understanding the development of behavioral and emotional problems in children and adolescence (Bell-Dolan, Foster, \& Mash, 2005; Mash \& Barkley, 2003). In a noteworthy example of a study designed to examine gender as moderator of the association between parenting and adolescent problem behavior, Schulte, Ramo, and Brown (2009) found that gender moderated the association between parenting and adolescent alcohol use, with monitoring influencing boys more strongly than girls. Although previous research linked parental monitoring to substance use in boys and girls (Schinke, Fang, \& Cole, 2008; Webb, Bray, Getz, \& Adams, 2002), some evidence suggests that monitoring influences boys' alcohol use more strongly than girls (Barnes, Reifman, Farrell, \& Dintcheff, 2000). By examining the interaction of social and biological influences (i.e., adolescent sex, social construction of gender, and parenting behavior), we may be able to gain a better understanding of the processes and mechanisms underlying gender effects on adolescent behavior (Mash \& Barkley, 2003), particularly in regard to adolescent sexual risk behavior.

\subsection{Selection criteria for the current review}

The purpose of this review is to examine whether adolescent gender moderates the relation between parenting and sexual risk behavior among youth. This literature review was conducted by searching electronic databases (PsycInfo, PubMed, Sociological Abstracts) to identify cross-sectional and longitudinal studies of youth sexual behavior published in peer- 
reviewed journals between 1990 and 2011. To be included in this literature review, a study needed to satisfy the following conditions: a) the study sampled both male and female adolescents (ages 10-18) from the United States to allow meaningful comparisons of gender, b) the study examined at least one parenting construct as a predictor (e.g., warmth/ support, behavioral control, psychological control), c) the study examined one or more sexual risk behaviors as outcome variables, d) the study examined gender as a moderator of the relationship between parenting and youth sexual risk behavior. For the purposes of this review, studies were included that examined moderation of gender in the following ways: re-running analyses separately by gender or creating an interaction term. Importantly, the majority of studies retained for this review defined sexual risk behavior as the initiation of sexual intercourse (e.g., oral, anal or vaginal) during adolescence or created an index of risky behaviors associated with intercourse (e.g., having unprotected sex, multiple partners, etc.). Accordingly, we report associations between parenting variables of interest for this study (i.e., monitoring, warmth, and psychological control) and sexual outcome variable(s) for each study.

Exclusion criteria were: a) the study sampled either males or females only (thus lacking the desired comparison of gender), b) the study examined only intentions or attitudes toward sexual behavior (but not actual behavior), c) the study sampled maltreated children with a history of abuse or neglect (there may be unique processes and factors to consider when examining the risk behavior of maltreated youth), d) the study sampled adolescents who are parents (whose parenting processes may be substantively different from older parents), (e) the study examined other parent behavior variables that do not meet the traditional definitions defined for parenting style (such as parental substance use, legal involvement, etc.) or variables that may be associated with parenting style but are not constructs typically used to reflect parenting style (e.g., shared meal time), and f) the study examined teenage pregnancy as an outcome variable (sexual risk behavior was the primary outcome of interest, versus pregnancy). If multiple measures of constructs of interest were used in a single study that examined gender as a moderator, all associations were reported. Similarly, when multiple studies presented findings from the same data set (e.g., ADD HEALTH), the findings were included in the review given that the associations examined were unique across studies. Search terms included sexual risk behavior, sexual risk taking, sexual intercourse, coitus, health risk behavior, parenting, parenting style, specific parenting terms (e.g., warmth, behavioral control, monitoring), gender, and bioloical sex. Searches were limited by the terms adolescent, adolescents, or adolescence.

\section{Gender as a moderator: a review of findings}

\subsection{Methodological quality}

The investigative nature of this initial review of gender as a moderator of the relationship between parenting variables and adolescent sexual risk behavior allowed for a wide scope in regard to study methods (please refer to Table 1 for more specific descriptions of study methodologies). Although the variability in study methodology may account for some of the variance in the study findings, the authors closely examined methodological variables among studies and did not find major thematic differences in terms of analytic methods, age ranges, other sample demographics, and/or measures utilized. The majority of studies included in this review utilized logistic or hierarchical regression analyses (e.g., 72\%), although a few studies used more sophisticated statistical analyses (e.g., Structural Equation Modeling, Multilevel Growth Modeling); yet, the authors identified no apparent trends in the findings based on data analytic methods. Additionally, the two groups (moderation versus not) did not appear to differ significantly in terms of age of the youth; for example, most studies examined youth in the 12-17 year range, with the mean being around 14 years old on average (see Table 1 for details). Also, in terms of measures utilized, there did not 
appear to be major differences in regard to the variability of measures (e.g., risk indicators, particular measures of monitoring, etc.) and the study findings and, in fact, constructs used across studies were the same in many cases.

Although interactions of methodological variability were not the central focus of this review, the issue is important and is ripe for future research in order to align the field in a more consistent application of measures, analytic plans, etc. Furthermore, in a special section of the Journal of Clinical Child and Adolescent Psychology on gender differences within child and adolescent psychopathology, Kistner (2009) emphasized that advancing the methodologically rigorous testing of gender is a promising direction for future research on sex differences, as well. In spite of the methodological variability across studies, this review provides an important preliminary examination of gender as moderator of findings between parenting variables and sexual risk behavior as an important step in integrating the findings in the literature.

\subsection{Behavioral control}

Of the 25 empirical studies retained for this review (see Table 1), 76\% examined behavioral control (e.g., monitoring) as a predictor of adolescent sexual behavior $(n=19)$. More than half of these studies (61\%) found higher levels of parental monitoring to be associated with less sexual risk behavior for both males and females. A considerable amount of empirical evidence in the extant literature supports the link between higher levels of behavioral control and lower levels of youth sexual risk behavior (for a review, see Buhi \& Goodson, 2007). Thus, the fact that the majority of studies found monitoring to be an important predictor for both male and female youth remains consistent with the greater literature on parenting and youth sexual risk behavior. Again, the rigor of the studies did not appear to be a distinguishing factor between the studies that found gender to be a moderator versus those that did not; both included cross-sectional and longitudinal data. Interestingly, the majority of studies that found gender equivalence were comprised of predominantly European American samples (Ary et al., 1999; Bersamin et al., 2008; Biglan et al., 1990). In contrast, five studies comprised of predominantly ethnic minority youth found monitoring to be more important for boys (Borawski, Ievers-Landis, Lovegreen, \& Trapl, 2003; Kapungu, Holmbeck, \& Paikoff, 2006; Kincaid, 2011; Smith, 1997; Sneed, Strachman, Nguyen, \& Morisky, 2009).

In a cross-sectional study of an ethnically diverse sample of adolescents (51\% European American, 36\% African American, 21\% Hispanic),Borawski et al. (2003) found that higher levels of parental monitoring were associated with safer sex practices (e.g., consistent condom use) for males, but not for girls. They report that the male and female samples were similar with regard to demographic characteristics, with the exception of age (i.e., boys were two months older than girls on average).Borawski et al.'s (2003) findings suggest that monitoring may be a particularly important predictor for male versus female adolescents. Given that the study was cross-sectional in design, conclusions of causality cannot be drawn from this study alone. Yielding further support, however, a second study of longitudinal study of African American and Latino youth from urban neighborhoods also found that lower levels of monitoring were associated with early sexual activity for boys only, even after accounting for age (Smith, 1997). Additionally, in a cross-sectional structural equation modeling (SEM) analysis of youth from African American single mother homes, monitoring was associated with fewer problem behaviors (e.g., sexual risk behavior, substance use, etc.) for boys, but not girls (Kincaid, 2011).

Fourth, in a cross-sectional study of mostly-minority youth, less parental monitoring was associated with higher chances that the adolescent boys would engage in precoital (kissing, touching) and coital (oral, anal and vaginal) sexual behaviors (Sneed et al., 2009). Although many studies examined only sexual intercourse, the findings from Sneed et al. (2009) 
suggest that monitoring is important for a range of sexual behavior (from precoital to coital) among ethnic-minority adolescent males. This is particularly important for sexual risk behavior interventions, given the empirical evidence that indicates adolescents who want to delay sex engage in fewer precoital activities than those who initiate sexual intercourse (Miller et al., 1997). By delaying precoital activity, parental monitoring may effectively delay early sexual initiation among males.

Fifth, in another longitudinal study of African American youth living in impoverished neighborhoods, Kapungu et al. (2006) reported that boys reared in low control/high warmth (e.g., permissive parenting) environments were particularly at risk for pre-sexual risk behaviors and sexual intercourse. Without the balance of behavioral control, higher levels of maternal warmth heightened the chances that African American adolescent boys would engage in sexual risk behavior (Kapungu et al., 2006). While this study points to the critical balance of warmth and behavioral control as central components of optimal parenting (Baumrind, 1991b; Jones et al., 2005), the results suggest that a parenting deficit in behavioral control may be particularly detrimental for boys. This is consistent with Baumrind and Black's (1967) early work, as well, which also stated that boys tended to do worse in permissive environments.

Across these five studies, monitoring was a more salient predictor for boys. Three of the four studies were predominantly ethnic minority samples (African American, Hispanic, and Asian American, and Pacific Islander; Kapungu et al., 2006; Smith, 1997; Sneed et al., 2009), and one study was evenly split between ethnic minority youth and European American youth (Borawski et al., 2003). These findings may contribute some support to a growing literature that suggests it may be optimal for parents to shift the relative balance of warmth/support and monitoring/ control depending on the context (e.g., urban neighborhoods, see Jones, Forehand, Brody, \& Armistead, 2003) or behavior under study (Bean, Bush, McKenry, \& Wilson, 2003; Brody \& Flor, 1998; Luster \& Small, 1994). In fact, several studies of African American parenting suggest that the emphasis on parental control and disciplinary practices may be more appropriate and adaptive given environments in which many African American youth are reared (e.g., Cauce et al., 1996; Kelley, Power, $\&$ Wimbush, 1992). This also points to a need for further studies examining gender and race/ ethnicity as moderators of the association between parenting and sexual behavior, a consideration discussed later in this review.

There are several hypothesized theoretical explanations that are offered for the role of monitoring as a particularly salient factor for male adolescents. From a social learning perspective, boys tend to place more value on authority and control (Feldman, Turner, \& Araujo, 1999; Maccoby, 1990). From this viewpoint, high-quality parenting processes involving skillful behavioral control strategies (e.g., supervision, rule-setting) may have more of an impact on male youth. On a related note, Jackson and Foshee (1998) attribute gender differences to family socialization processes of males and females. These investigators suggest that parental 'demandingness' (a construct related to behavioral control) is more protective for boys (given parents' emphasis on young boys' behavioral compliance), whereas parental responsiveness is a stronger protective factor for girls who tend to place more emphasis on interpersonal relationship processes. Furthermore, Li et al. (2000) found that parents monitor and supervise their sons differently than their daughters. If parental monitoring is influenced by the gender of the adolescent, behavioral control might differ in its effect for boys and girls.

\subsection{Warmth/relationship quality}

Approximately two thirds (64\%) of the studies retained for this review examined parental warmth/support as a predictor of adolescent sexual behavior $(n=16)$. In total, four studies 
(approximately $25 \%$ of studies examining warmth/support) found higher levels of parental warmth to be associated with less sexual risk behavior for both males and females in 1 crosssectional (Biglan et al., 1990) and three longitudinal studies (Bersamin et al., 2008; Sieving, McNeely, \& Blum, 2000; Smith, 1997). In contrast, seven studies (44\% of those examining parental warmth) reported that warmth/support was a stronger predictor sexual risk behavior for females in five longitudinal studies (Henrich, Brookmeyer, Shrier, \& Shahar, 2006; Kapungu et al., 2006; McNeely et al., 2002; Miller et al., 1997; Pearson, Muller, \& Frisco, 2006) and two cross-sectional studies (Borawski et al., 2003; Rose et al., 2005). No studies that found warmth to be more important for boys than girls.

In the majority of studies examining parental warmth, higher levels of parental support and strong parent-child relationships significantly decrease the odds of sexual risk behavior among boys and girls; however, this effect was particularly true among females. In their cross-sectional study of ethnically diverse adolescents, Borawski et al. (2003) found that perceived parental trust (e.g., an indirect marker of positive relationship quality) was a more important predictor for girls' recent sexual activity. Second, in a longitudinal study of ethnically diverse youth, girls with high initial levels of parent connectedness were less likely to engage in sexual risk behavior over time, but this effect did not hold true for boys (Henrich et al., 2006). In a third study, Miller et al.'s (1997) longitudinal study found that family process variables showed little relationship to sexual behavior among males, but mothers' warmth was strongly related to the age of sexual initiation among daughters. Fourth, for adolescents in the Add Health Study (e.g., a longitudinal study of adolescent health following a nationally representative sample of students in grades 7 through 12), greater parent-child relationship quality predicted later initiation of sexual intercourse for females, but not for males (Pearson et al., 2006).

Although the aforementioned studies were based on adolescent report of the parent-child relationship, the association also holds true for studies that examined caregiver-report of warmth/relationship quality. For example, McNeely et al. (2002) found that mother-reported satisfaction with the parent-child relationship quality predicted delayed sexual intercourse among daughters. In a longitudinal study of African American single-mother families from impoverished neighborhoods (Kapungu et al., 2006), both adolescent and parent report of relationship quality corroborated the findings that warmth/support is a particularly important predictor for girls' sexual behavior. Girls reared in high control/low warmth (e.g., authoritarian) homes were particularly at-risk for early sexual behaviors (i.e. playing touching games; Kapungu et al., 2006). Similarly, among a younger sample of 5th grade adolescents, parents who reported the poorest relationship quality had daughters who were significantly more likely to have had sexual intercourse than parents who reported better relationships with their female adolescents (Rose et al., 2005). At higher levels of relationship quality, girls were less likely to have sexual intercourse compared with sons of parents who reported higher levels of relationship quality.

According to the findings of this literature review, the majority of studies examining gender as a moderator of the association between parenting and sexual risk behavior point to parent-child relationship quality as a more salient factor for girls versus boys. The interpersonal context has been identified as a major contributor to young girls' sexual development (Feldman et al., 1999), suggesting that relationships with parents may influence girls' sexual decision-making more than boys (Gilligan, 1982). Furthermore, interpersonal fulfillment, which may be augmented by a strong and supportive parent-child relationship, has been identified as a protective factor in the study of resilience among female adolescents (Siqueira \& Diaz, 2004). 
Adolescent females characteristically ascribe greater meaning to interpersonal connection and social bonding (Feldman et al., 1999); therefore, they may place more of an emphasis on the parent-child relationship during adolescence. For this reason, girls may be more affected by their parents' ability to provide a warm and supportive relationship. For females, the parent-child relationship may be a more salient factor in the development of self-worth, as well as the prototypical model of close relationships.

As young girls strive to establish a sexual identity (Siqueira \& Diaz, 2004), the value ascribed to interpersonal relationships may contribute to sexual risk behavior in a number of ways. First, adolescents who lack a strong relationship with a caregiver may seek connections with others in the form of sexual intimacy as a means of establishing an interpersonal identity or self-construal (Cross \& Madson, 1997). Furthermore, adolescents who lack a relationship with a supportive, warm adult figure may have psychosocial adjustment difficulties or lower self-esteem, which, in turn, may lead to earlier sexual activity among females as a means of compensating for deficits within the context of the parent-child relationship (Chilman, 1979).

Of note, five studies included in this review utilized data from the National Longitudinal Study of Adolescent Health (i.e., Add Health dataset). Sieving et al. (2000), Pearson et al. (2006), and McNeely et al. (2002) focused on adolescents in a similar age range ( $M=9$ th grade, or 14-15 years of age) and all focused on adolescents' first sexual intercourse as the outcome of interest. Each of these three studies found that gender was a moderator between parenting and sexual debut and parental warmth/support was a stronger predictor sexual risk behavior for females than for males. Others who analyzed Add Health data (Cox, 2006; Henrich et al., 2006) focused on older adolescents (i.e., ages 17 and 18). Henrich et al. (2006) examined a more comprehensive outcome measure of sexual risk behavior by examining parenting in relation to a sexual risk behavior index (comprised of 5 sexual risk behaviors); regardless of the change in age and outcome measure, gender remained a significant moderator as parental warmth/support emerged as more important for girls than boys. In contrast, Cox (2006) did not find that gender moderated the link between parenting and condom use at age 18 .

Of course, given the common dataset for these studies, it is certainly possible that sample overlap inflates the percentage of studies that find support for gender moderation effects. As noted earlier, such issues merit further attention in quantitative reviews of the literature which will be possible when attention to gender increases in this literature.

\subsection{Emerging themes: psychological control}

Although studies examining parenting and youth sexual risk behavior focus less attention on psychological control than behavioral control, several studies suggest that psychological control may also be an important predictor of increased sexual risk behavior. Three studies have examined the link between psychological control and sexual risk behavior (Kincaid, 2011; Miller et al., 1997; Rodgers, 1999), relative to the larger literature that has examined behavioral control as a predictor of sexual risk behavior. In all three studies, results suggested that psychological control is a predictor of increased sexual risk behavior for girls, but not boys. Examining data from a longitudinal survey of European American and African American adolescents across the United States, Miller et al. (1997) found that higher levels of maternal psychological control (e.g., love withdrawal) were associated with an earlier age of sexual initiation for girls. In a study of mostly European American youth from Midwestern U.S., Rodgers (1999) found that higher levels of fathers' psychological control, but not mothers' psychological control, made it more likely for sexually active daughters to engage in high-risk sexual behavior (e.g., defined by number of partners, type of contraception, and frequency of contraception use). Rodgers (1999) suggests that higher 
levels of psychological control hinders adolescent development of psychological and moral maturity, subsequently increasing the chances of risk taking via engagement in unprotected or early sexual behavior. Additionally, Kincaid (2011) found that psychological control was associated with higher levels of sexual risk behavior/problem behavior among girls from African American single mother homes. In spite of the variability across these studies (e.g., maternal versus paternal psychological control, family composition, etc.), the findings were consistent. Although these three studies represent a very preliminary examination of the association between psychological control and adolescent sexual risk behavior, they suggest that this particular parenting practice may play an important role in predicting adolescent sexual risk behavior, particularly among females.

\section{Discussion}

In light of the complex interplay between parenting and youth sexual risk behavior, the results of this review suggest that male and female youth may require different parental approaches in order to buffer sexual risk taking during adolescence. Whereas the literature suggests that the majority of youth benefit from skillful, effective monitoring (e.g., supervision, knowledge of youth activities), there is a trend to suggest that monitoring may be more protective for boys in regard to sexual risk behavior, and particularly among boys from ethnic minority backgrounds. This is consistent with the developmental psychopathology literature, which maintains that resilient boys benefit from households characterized by more structure and consistent rules (Werner, 1995).

Additionally, the findings suggested that higher parent-child relationship quality (e.g., high levels of warmth and support) may be a particularly important protective factor for girls. This hypothesis is further supported by the fact that multiple studies included in this review found the effect to hold true over time (Henrich et al., 2006; Kapungu et al., 2006; McNeely et al., 2002; Miller et al., 1997; Pearson et al., 2006). This is consistent with prior work suggesting that girls tend to be more interpersonally oriented than boys (Feldman et al., 1999; Siqueira \& Diaz, 2004; Werner, 1995); thus, girls may be more likely to be affected by deficits in the parent-child relationship. Of note, some research suggests that girls may be more affected by a lack of positive parenting behavior (Kavanagh \& Hops, 1994). Although less attention is given to the function of psychological control, three studies suggested that psychological control may also be detrimental for female adolescents, in particular (Kincaid, 2011; Miller et al.,1997; Rodgers, 1999). Overall, the findings of this review suggest that adolescent gender is a critical factor to consider when examining the link between parenting and adolescent sexual risk behavior.

\subsection{Methodological considerations and areas of future research}

Broadly speaking, the variations in operationalization and measurement of parenting constructs have led to some disagreement around what parenting behaviors are actually being assessed (Stattin \& Kerr, 2000). Furthermore, there is a dearth of information around how these parenting behaviors may differ in regard to boys and girls, both in perception from youth and implementation from parents. To ensure that investigators are clearly measuring the parenting processes as they relate to boys and girls, more gender-specific parenting measures are needed to elucidate the impact of these parenting constructs on the sexual risk behavior of both boys and girls.

Additionally, the vast majority of studies that relied on parent-report of parenting utilized mothers, with a few notable exceptions including fathers (Bersamin et al., 2008; Coley et al., 2009; Rodgers, 1999). The majority of caregivers, however, including those in single-parent households, do not parent alone (Jones, Zalot, Chester, Foster, \& Sterrett, 2007). By 
including father and coparent-report, investigators will be able to obtain a more complete picture of the role of parenting behavior in predicting risk behavior.

Among the few studies that did examine fathers' parenting, some interesting findings emerged. For example, Rodgers (1999) found that paternal versus maternal exercise of psychological control was a more important predictor of girls' increased sexual risk behavior. Additionally, Coley et al. (2009) found that father knowledge was more protective against girls' sexual risk taking, as well. These findings allude to parent gender as an important moderator to consider in future research, as well. Recently, parent gender has received more empirical attention in the literature (Crick \& Zahn-Waxler, 2003; Phares, 1996). For example, in a study by Papini, Farmer, Clark, and Micka (1990), both the gender of the adolescent and the gender of the parent affected the degree and frequency of communication and monitoring in the family. Similarly, in a study of harsh physical and verbal discipline and child problem outcomes, McKee et al. (2007) found that boys received more harsh discipline than girls, with fathers utilizing more harsh physical discipline with boys (compared to mothers). In order to examine the complex interactions between parent and child gender, it may be particularly valuable to distinguish the gender of both the adolescent and the parent in future studies.

\subsubsection{Transactional perspectives}

Considering the transactional nature of child behaviors and parenting (Coley et al., 2009; Sameroff, 1975), it may also be true that higher levels of adolescent risk behavior lead parents to adjust parenting behaviors (e.g., ramp up their monitoring as adolescents mature). It will be important for future studies to examine the transactional nature of the parent-child relationship via longitudinal designs, as well as the impact of changes in parenting over time. From the transactional and family system perspective (Coley et al., 2009; Sameroff, 1975), the behaviors within a family (both parent and adolescent behaviors) act as part of bidirectional, mutually influential system. In the same way that parental influence shapes child behavior, parents also react to the child's characteristics and behaviors (Bell, 1968; Crouter \& Booth, 2003; Sameroff, 1975). For example, risky behaviors among adolescents may lead parents to become less involved with their children, and those less positive parenting interactions may then contribute to escalating sexual risk behavior (Coley et al., 2009).

\subsubsection{Measurement of adolescent sexual behavior}

Among the studies retained for this review, investigators measured 'sexual risk behavior' among adolescents in a variety of ways. The two most common ways of examining the outcome variable were assessing timing of adolescents' first sexual initiation ( $n=8$ studies) or creating an index of sexual risk behavior that accounted for various sexual risk behaviors ( $n=10$ studies). Other methods of assessing sexual risk behavior involved dichotomous measures of sexual activity ( $n=7$ studies), and condom use ( $n=2$ studies).

Although it is still common practice to assess sexual risk behavior in dichotomous terms (e.g., either the young person is having sex or they are not), a much more informative way of assessing risk behavior involves looking at the spectrum of possible sexual behavior (kissing and holding hands, laying together, oral sex, intercourse). By examining risk behavior in a more comprehensive manner, researchers might be able to fine-tune the connections between specific predictors and outcomes, and at different ages (e.g., low versus high-risk sexual behavior). Importantly, this information might allow a more sophisticated way to target parenting interventions for adolescents. By identifying where adolescents fall on the continuum of sexual behavior, risk-reduction interventions and strategies may be more effective by tailoring the information and messages to the actual level of sexual behaviors 
that is occurring for a particular adolescent or group of adolescents. For example, messages targeted to adolescents who have engaged in behaviors at the lower end of the continuum (e.g., kissing, petting) might focus on the positive aspects of not going 'too far' sexually (Sneed et al., 2009). For adolescents who have already engaged in heavy petting or oral sex, these interventions might do well to focus on behavioral motivations for engaging in condom use as these youth are likely to progress to penetrative sex (Sneed et al., 2009).

\subsection{Gender and race/ethnicity interactions}

Although the current study focused on gender, there are other factors that moderate the relationship between parenting and adolescent sexual risk behavior. Although a review of all potential moderators was beyond the scope of the current review, a recent review of the developmental correlates of sexual intercourse among U.S. adolescents emphasized the importance of both gender and race/ethnicity as correlates of adolescent sexual risk behavior (Zimmer-Gembeck \& Helfand, 2008). While the purpose of the current review was primarily to examine the role of gender, race/ethnicity is another important factor to consider for future research on the link between parenting and adolescent sexual risk behavior. For example, four studies included in the current review found that monitoring was more important predictor for boys' sexual behavior than girls among predominantly ethnic minority samples (Borawski et al., 2003; Kapungu et al., 2006; Smith, 1997; Sneed et al., 2009).

Although very few studies retained in the Zimmer-Gembeck and Helfand review examined gender or race/ethnicity as moderators of the associations between sexual intercourse and proposed antecedents (e.g., parenting), the authors emphasize that most studies found associations between race/ethnicity and the onset of sexual intercourse. Furthermore, according to the Youth Risk Behavior Surveillance Report (CDC, 2008), the national statistics indicate that African American adolescents are more likely than European American adolescents to endorse that they have engaged in sexual intercourse. For example, two thirds (66.5\%) of African American youth reported having sexual intercourse, while less than half of European American youth reported ever having sexual intercourse (43.7\%). Interestingly, when race/ethnicity and gender are examined together, the patterns look different for African American boys and girls. On average, an African American adolescent male was 2.8 times more likely to have a history of sexual intercourse compared to White adolescent males; however, African American girls did not differ from girls in other ethnic groups (Zimmer-Gembeck \& Helfand, 2008).

Given the fact that higher rates of sexual risk behavior are reported among adolescents from ethnic minority backgrounds (CDC, 2008), at least among African American boys relative to girls, it will be particularly important for future work to consider both gender and racial/ ethnic differences involved in the processes leading to sexual risk behavior. The findings of this review suggest that monitoring may be particularly salient for ethnic minority boys; however, the mechanisms of this link would benefit from additional research on cultural values for boys and girls within different racial and ethnic groups. Whenever possible, it will be particularly important for investigators to examine gender and race/ethnicity as potential moderators of associations between parenting and adolescent sexual behavior (ZimmerGembeck \& Helfand, 2008).

\subsection{Clinical implications for gender-specific interventions}

The role of gender as a moderator of the relationship between parenting and sexual risk behavior is an important consideration for clinicians working with parents of adolescents, as well. In the context of clinical work, it is essential for parents to be aware of the unique biological, social and emotional challenges of adolescence in order to skillfully help their 
child navigate their way through adolescence to adulthood. For clinicians who work alongside families in need of additional support and guidance in this domain, it is of critical importance to evaluate the role of gender as a moderating factor in the link between parenting processes and adolescent sexual risk behavior. Optimal parenting requires flexibility and adaptability to meet the particular needs of an individual child or adolescent in a developmentally-appropriate manner; ideally, parents will modify their approaches to child-rearing by taking into account the individual factors which make their child unique (e.g., age, gender, temperament, cognitive ability, etc.). The results of this review suggest that gender is an important factor to consider for parenting adolescents in a manner that reduces sexual risk behavior.

The findings of this review have the potential to inform the case conceptualization and treatment delivery within parenting interventions and family therapy more broadly. Specifically, the review findings suggest that parents may need to be particularly attentive to the relationship needs of female adolescents. The majority of the studies that examined gender as a moderator of the relationship between parenting and adolescent risk behavior found that the amount of warmth and support young girls received had a direct bearing on their sexual risk behavior, both cross-sectionally and over time. Although most studies indicated that behavioral control/monitoring also had a protective effect for girls in regard to reducing sexual risk behavior, the use of psychological control was suggested as a particularly harmful parenting practice for female adolescents in three noteworthy studies. These findings suggest that the parent-child relationship is a particularly salient factor to consider when the goal is to delay or reduce sexual risk behavior among females.

Review findings also suggest that a next step may involve the development and implementation of family-based, gender-specific, culturally-sensitive models to enhance the effectiveness of prevention and intervention programs targeting safer sex practices among adolescents. In fact, gender is receiving mounting attention within existing parenting and family-based interventions aimed at decreasing adolescent sexual risk behavior (DiClemente et al., 2008). To date, the most successful interventions for curbing adolescent high-risk sexual behavior are those that are specifically tailored and delivered to a specific subgroup of adolescents (e.g., African American females; DiClemente et al., 2008, 2004; St. Lawrence et al., 1995). In terms of reducing STD and HIV-associated sexual risk behaviors, tailored interventions are more effective relative to general interventions (DiClemente et al., 2008). Successful tailored interventions recognize adolescents as a heterogeneous group and take into account factors such as gender differences, ethnicities/cultures, and behavioral risk characteristics to enhance the applicability of the intervention to the individual adolescent. One noteworthy example of a theory-guided, gender-tailored and culturally appropriate sexual risk reduction program is the SiHLE intervention (Sistas Informing, Healing, Living and Empowering; Wingood \& DiClemente, 2000). SiHLE applied a gender-relevant theoretical framework to highlight social processes prevalent in the lives of African American girls. Specifically, the gender-tailored SiHLE intervention emphasizes developing relational skills and assertiveness skills in order to promote healthy relationship choices and sustain sexual health (Wingood \& DiClemente, 2000). The success of the SiHLE intervention strongly supports movement toward gender-tailored parenting interventions designed to reduce or delay adolescent sexual risk behavior, and this review suggests that future interventions would do well to place greater emphasis on the parent-child relationship as a medium for providing adolescents with the tools they need to navigate healthy relationships. Given the central role of the family in shaping adolescent developmental processes, gender-specific interventions like SiHLE would also benefit from including the parents as behavioral change agents (DiClemente et al., 2008). 


\section{Conclusions}

In conclusion, it cannot be understated that parents act as primary socializing agents who strongly influence their adolescents' behaviors and expectancies regarding timing and involvement in sexual behaviors and relationships (Coley et al., 2009). Optimally, as parents prepare their children for adulthood, they engage in parenting to protect their adolescents from involvement in sexual risk behavior; ultimately, however, parents also play a major role in raising individuals who are prepared for healthy intimacy and decision-making regarding sexual behaviors. In order to prepare youth for a healthy experience of sexual intimacy and interpersonal relationships, it is essential that clinicians and parents are attuned to the unique needs of adolescent males and females, rather than grouping both as homogeneous entities.

Whereas the review findings suggest that monitoring is protective against sexual risk behavior for most adolescents (but slightly more protective for ethnic minority boys' sexual risk behavior), the amount of parental warmth and emotional connection experienced within the parent-child context appears to be an especially salient protective factor for adolescent girls. The results of this review maintain that gender is an important moderator of the association between parenting and adolescent sexual risk behavior. Furthermore, the results support a) movement toward gender-specific tailored interventions to reduce adolescent sexual risk behavior, b) further research on gender processes as an important mechanism for understanding adolescent development, c) increased sensitivity to racial/ethnic differences as a potential moderator, and d) refinement of the methodology and measurement within the field.

\section{Acknowledgments}

Funding for this project was provided by grants from the Ethnicity, Culture and Health Outcomes, a Junior Faculty Development Grant, a University Research Council Grant, and pilot funding from the UNC Center for AIDS Research (CFAR; 9P30 AI050410). Additional support was provided by a Mentored Research Development Award from the Centers for Disease Control and Prevention (K01 PS000795).

We would also like to sincerely thank and recognize Drs. Andrea Hussong and Enrique Neblett, Jr. for their feedback on earlier drafts of this manuscript.

\section{References}

Ary DV, Duncan TE, Biglan A, Metzler CW, Noell JW, Smolkowski K. Development of adolescent problem behavior. Journal of Abnormal Child Psychology. 1999; 27(2):141-150. doi:10.1023/A: 1021963531607. [PubMed: 10400060]

Barber BK. Parental psychological control: Revisiting a neglected construct. Child Development. 1996; 67(6):3296-3331. doi:10.2307/1131780. [PubMed: 9071782]

Barber, BK. Intrusive parenting: How psychological control affects children and adolescents. American Psychological Association; Washington, D.C.: 2002. doi:10.1037/10422-000

Barnes GM, Reifman AS, Farrell MP, Dintcheff BA. The effects of parenting on the development of adolescent alcohol misuse: A six-wave latent growth model. Journal of Marriage and the Family. 2000; 62:175-186. doi:10.1111/j.1741-3737.2000.00175.x.

Baumrind D. Reciprocal rights and responsibilities in parent-child relations. Journal of Social Issues. 1978; 34(2):179-196. doi:10.1111/j.1540-4560.1978.tb01038.x.

Baumrind, D. Effective parenting during the early adolescent transition. In: Cowan, PA.; Hetherington, EM., editors. Family transitions. Lawrence Erlbaum Associates Inc.; Hillsdale, NJ, England: 1991. p. 111-163.

Baumrind D. The influence of parenting style on adolescent competence and substance use. The Journal of Early Adolescence. 1991; 11(1):56-95. doi: 10.1177/0272431691111004. 
Baumrind D, Black AE. Socialization practices associated with dimensions of competence in preschool boys and girls. Child Development. 1967; 38(2):291-327. doi: 10.2307/1127295. [PubMed: 6057386]

Bean RA, Bush KR, McKenry PC, Wilson SM. The impact of parental support, behavioral control, and psychological control on the academic achievement and self-esteem of African American and European American adolescents. Journal of Adolescent Research. 2003; 18(5):523-541. doi: 10.1177/0743558403255070.

Bell RQ. A reinterpretation of the direction of effects in studies of socialization. Psychological Review. 1968; 75(2):81-95. doi:10.1037/h0025583. [PubMed: 4870552]

Bell-Dolan, DJ.; Foster, SL.; Mash, EJ. Handbook of behavioral and emotional problems in girls. Kluwer Academic/Plenum; New York: 2005. doi:10.1007/b107822

Berman NG, Parker RA. Meta-analysis: Neither quick nor easy. BMC Medical Research Methodology. 2002; 2(10):1-9. doi:10.1186/1471-2288-2-10. [PubMed: 11860604]

Bersamin M, Todd M, Fisher DA, Hill D, Grube JW, Walker S. Parenting practices and adolescent sexual behavior: A longitudinal study. Journal of Marriage and the Family. 2008; 70:97-112. doi: 10.1111/j.1741-3737.2007.00464.x. [PubMed: 19750131]

Biglan A, Metzler CW, Wirt R, Ary D, Noell J, Ochs L, et al. Social and behavioral factors associated with high-risk sexual behavior among adolescents. Journal of Behavioral Medicine. 1990; 13(3): 245-261. doi:10.1007/BF00846833. [PubMed: 2213868]

Borawski EA, Ievers-Landis CE, Lovegreen LD, Trapl ES. Parental monitoring, negotiated unsupervised time, and parental trust: The role of perceived parenting practices in adolescent health risk behaviors. Journal of Adolescent Health. 2003; 33:60-70. doi: 10.1016/ S1054-139X(03)00100-9 DOI:dx.doi.org. [PubMed: 12890596]

Brody GH, Flor DL. Maternal resources, parenting practices, and child competence in rural, singleparent African American families. Child Development. 1998; 69(3):803-816. [PubMed: 9680686]

Brody GH, Murry VM, Gerrard M, Gibbons FX, McNair L, Brown AC, et al. The strong African American families program: Prevention of youths' high-risk behavior and a test of a model of change. Journal of Family Psychology. 2006; 20(1):1-11. doi:10.1037/0893-3200.20.1.1. [PubMed: 16569084]

Bronfenbrenner, U. Toward a theoretical model for the analysis of parent-child relationships in a social context. In: Glidewell, JC., editor. Parental attitudes and child behavior. Charles Thomas; Oxford, England: 1961. p. 90-109.

Bronfenbrenner, U. The ecology of human development. Harvard University Press; Cambridge, MA: 1979.

Brown, AB.; Flanigan, C. 14 and younger: The sexual behavior of young adolescents. National Campaign to Prevent Teen Pregnancy; Washington, D.C.: 2003.

Buhi ER, Goodson P. Predictors of adolescent sexual behavior and intention: A theory-guided systematic review. Journal of Adolescent Health. 2007; 40:4-21. doi: 10.1016/j.jadohealth. 2006.09.027. [PubMed: 17185201]

Cauce, AM.; Hiraga, Y.; Graves, D.; Gonzales, H.; Ryan-Finn, K.; Grove, K. African-American mothers and their adolescent daughters: Closeness, conflict \& control. In: Leadbeater, B.; Way, N., editors. Urban girls: Resisting stereotypes, creating identities. New York University Press; New York: 1996. p. 100-116.

Center for Disease Control and Prevention. Youth risk behavior surveillance United States, 2007. Morbidity and Mortality Weekly Report. 2008; 57(SS-4):1-131. [PubMed: 18185492]

Chilman, C. Adolescent sexuality in a changing American society: Social and psychological perspectives. U.S. Government Printing Office; Washington, D.C.: 1979.

Coley RL, Votruba-Drzal E, Schindler HS. Fathers' and mothers' parenting practices and responding to adolescent sexual risk behaviors. Child Development. 2009; 80(3):808-827. doi:10.1111/j. 1467-8624.2009.01299.x. [PubMed: 19489905]

Costa FM, Jessor R, Donovan JE, Fortenberry JD. Early initiation of sexual intercourse: The influence of psychosocial uncoventionality. Journal of Research on Adolescence. 1995; 5(1):93-121. doi: 10.1207/s15327795jra0501_5. 
Cox MF. Racial differences in parenting dimensions and adolescent condom use at sexual debut. Public Health Nursing. 2006; 23(1):2-10. doi:10.1111/j.0737-1209.2006.230102.x. [PubMed: 16460415]

Crick NR, Zahn-Waxler C. The development of psychopathology in females and males: Current progress and future challenges. Development and Psychopathology. 2003; 15:719-742. doi: 10.1017/S095457940300035X. [PubMed: 14582938]

Cross SE, Madson L. Models of the self: Self-construals and gender. Psychological Bulletin. 1997; 122(1):5-37. doi:10.1037/0033-2909.122.1.5. [PubMed: 9204777]

Crouter, AC.; Booth, A., editors. Children's influence on family dynamics: The neglected side of family relationships. Erlbaum; Mahwah, NJ: 2003.

Cummings, EM.; Davies, PT.; Campbell, SB. Developmental psychopathology and family process: Theory, research, and clinical implications. Guilford Press; New York, NY, US: 2000.

DiClemente RJ, Crittenden CP, Rose E, Sales JM, Wingood GM, Crosby RA, et al. Psychosocial predictors of HIV-associated sexual behaviors and the efficacy of prevention interventions in adolescent at-risk for HIV infection: What works and what doesn't work? Special Issue: Psychosocial influences in HIV. 2008:598-605.

DiClemente RJ, Wingood GM, Harrington KF, Lang DL, Davies SL, Hook EW, et al. Efficacy of an HIV prevention intervention for African American adolescent girls: A randomized controlled trial. Journal of the American Medical Association. 2004; 292:171-179. doi:10.1001/jama.292.2.171. [PubMed: 15249566]

Dittus P, Miller KS, Kotchick BA, Forehand R. Why parents matter!: The conceptual basis for a community-based HIV prevention program for the parents of African American youth. Journal of Child and Family Studies. 2004; 13(1):5-20. doi: 10.1023/B:JCFS.0000010487.46007.08.

Fagot, B. Parenting boys and girls. In: Bornstein, MH., editor. Handbook of parenting, volume 1: Children and parenting. Lawrence Erlbaum Association; Hillsdale, NJ: 1995. p. 163-183.

Feldman SS, Turner RA, Araujo K. Interpersonal context as an influence on sexual timetables of youths: Gender and ethnic effects. Journal of Research on Adolescence. 1999; 9(1):25-52. doi: 10.1207/s15327795jra0901_2.

Gilligan, C. In a different voice: Psychological theory and women's development. Harvard University Press; Cambridge, MA: 1982.

Gray MR, Steinberg L. Unpacking authoritative parenting: Reassessing a multidimensional construct. Journal of Marriage \& the Family. 1999; 61(3):574-587. doi:10.2307/353561.

Hawkins JD, Weis JG. The social development model: An integrated approach to delinquency prevention. The Journal of Primary Prevention. 1985; 6(2):73-97. doi:10.1007/BF01325432.

Henrich CC, Brookmeyer KA, Shrier LA, Shahar G. Supportive relationships and sexual risk behavior in adolescence: An ecological-transactional approach. Journal of Pediatric Psychology. 2006; 31(3):286-297. [PubMed: 15827352]

Hoffman L. Changes in family roles, socialization, and sex differences. American Psychologist. 1991; 32:644-657. doi:10.1037/0003-066X.32.8.644.

Hops H. Age- and gender-specific effects of parental depression: A commentary. Developmental Psychology. 1995; 31:428-431. doi:10.1037/0012-1649.31.3.428.

Huebner AJ, Howell LW. Examining the relationship between adolescent sexual risk-taking and perceptions of monitoring, communication, and parenting styles. Journal of Adolescent Health. 2003; 33(2):71-78. doi:10.1016/S1054-139X(03)00141-1. [PubMed: 12890597]

Jackson C, Foshee VA. Violence-related behaviors of adolescents: Relations with responsive and demanding parenting. Journal of Adolescent Research. 1998; 13(3):343-359. doi: $10.1177 / 0743554898133006$

Jessor, R.; Jessor, SL. Problem behavior and psychosocial development: A longitudinal study of youth. Academic; New York: 1977.

Jessor R, Van Den Bos J, Vanderryn J, Costa FM, Turbin MS. Protective factors in adolescent problem behavior: Moderator effects and developmental change. Developmental Psychology. 1995; 31:923-933. doi:10.1037/0012-1649.31.6.923. 
Jones DJ, Forehand R, Brody G, Armistead L. Parental monitoring in African American, single mother-headed families: An ecological approach to the identification of predictors. Behavior Modification. 2003; 27(4):435-457. doi: 10.1177/0145445503255432. [PubMed: 12971121]

Jones DJ, Olson AL, Forehand R, Gaffney CA, Zens MS, Bau JJ. A family-focused randomized controlled trial to prevent adolescent alcohol and tobacco use: The moderating roles of positive parenting and adolescent gender. Behavior Therapy. 2005; 36(4):347-355. doi:10.1016/ S0005-7894(05)80116-9.

Jones DJ, Zalot A, Chester C, Foster S, Sterrett E. Childrearing in African American single mother families: A coparenting framework. Journal of Child and Family Studies. 2007; 16:671-683. doi: 10.1007/s10826-006-9115-0.

Kapungu CT, Holmbeck GN, Paikoff RL. Longitudinal association between parenting practices and early sexual risk behaviors among urban African American adolescents: The moderating role of gender. Journal of Youth and Adolescence. 2006; 35:787-798. doi:10.1007/s10964-006-9102-1.

Kavanagh K, Hops H. Good girls? Bad boys? Gender and development as contexts for diagnosis and treatment. Advances in Clinical Child Psychology. 1994; 16:45-79.

Kelley ML, Power TG, Wimbush DD. Determinants of disciplinary practices in low-income Black mothers. Child Development. 1992; 63:573-582. doi: 10.2307/1131347. [PubMed: 1600823]

Kincaid, C. Risk and resilience among African American single mother families: A closer look at parenting \& adolescent outcomes. Department of Psychology, University of North Carolina; Chapel Hill, North Carolina: 2011. Unpublished manuscript

Kincaid C, Jones DJ, Cuellar J, Gonzalez M. Psychological control associated with youth adjustment and risky behavior in African American single mother families. Journal of Child and Family Studies. 2011; 20(1):102-110. doi: 10.1007/s10826-010-9383-6.

Kistner JA. Sex differences in child and adolescent psychopathology: An introduction to the special section. Journal of Clinical Child and Adolescent Psychology. 2009; 38(4):453-459. doi: 10.1080/15374410902976387. [PubMed: 20183633]

Kotchick BA, Shaffer A, Forehand R. Adolescent sexual behavior: A multi-system perspective. Clinical Psychology Review. 2001; 21(4):493-519. doi:10.1016/S0272-7358(99)00070-7 DOI:dx.doi.org. [PubMed: 11413865]

Li X, Feigelman S, Stanton B. Perceived parental monitoring and health risk behaviors among urban low-income African American children and adolescents. Journal of Adolescent Health. 2000; 27:43-48. doi:10.1016/S1054-139X(99)00077-4 DOI:dx.doi.org. [PubMed: 10867351]

Li X, Stanton B, Feigelman S. Impact of perceived parental monitoring on adolescent risk behavior over 4 years. Journal of Adolescent Health. 2000; 27:49-56. doi: 10.1016/ S1054-139X(00)00092-6 DOI:dx.doi.org. [PubMed: 10867352]

Longmore MA, Eng AL, Giordano PC, Manning WD. Parenting and adolescents' sexual initiation. Journal of Marriage \& the Family. 2009; 71(4):969-982. doi:10.1111/j.1741-3737.2009.00647.x. [PubMed: 20160871]

Longmore MA, Manning WD, Giordano PC. Preadolescent parenting strategies and teens' dating and sexual initiation: A longitudinal analysis. Journal of Marriage and the Family. 2001; 63:322-335. doi:10.1111/j.1741-3737.2001.00322.x.

Luster T, Small SA. Factors associated with sexual risk-taking behaviors among adolescents. Journal of Marriage \& the Family. 1994; 56(3):622-632. doi:10.2307/352873.

Maccoby EE. Gender and relationships: A developmental account. American Psychologist. 1990; 45:513-520. doi:10.1037/0003-066X.45.4.513. [PubMed: 2186679]

Mash, EJ.; Barkley, RA. Child psychopathology. Guilford Press; New York: 2003.

Masten AS, Coatsworth JD. The development of competence in favorable and unfavorable environments: Lessons from research on successful children. American Psychologist. 1998; 53(2): 205-220. doi:10.1037/0003-066X.53.2.205. [PubMed: 9491748]

McKee L, Roland E, Coffelt N, Olson AL, Forehand R, Massari C, et al. Harsh discipline and child problem behaviors: The roles of positive parenting and gender. Journal of Family Violence. 2007; 22(4):187-196. doi:10.1007/s10896-007-9070-6.

McMahon, RJ.; Forehand, RL. Helping the noncompliant child: Family-based treatment for oppositional behavior. 2nd ed.. Guilford Press; New York, NY, US: 2003. 
McNeely C, Shew ML, Beuhring T, Sieving R, Miller BC, Blum R. Mothers' influence on the timing of first sex among 14- and 15-year-olds. Journal of Adolescent Health. 2002; 31:256-265. doi: 10.1016/S1054-139X(02)00350-6 DOI:dx.doi.org. [PubMed: 12225738]

Miller BC, Benson B, Galbraith KA. Family relationships and adolescent pregnancy risk: A research synthesis. Developmental Review. 2001; 21:1-38. doi: 10.1006/drev.2000.0513.

Miller BC, Norton MC, Curtis T, Hill EJ, Schvaneveldt P, Young MH. The timing of sexual intercourse among adolescents: Family, peer, and other antecedents. Youth Society. 1997; 29:5483. doi:10.1177/0044118X97029001003.

Papini DR, Farmer FF, Clark SM, Micka JC. Early adolescent age and gender differences in patterns of emotional self-disclosure to parents and friends. Adolescence. 1990; 25(100):959-976. [PubMed: 2275449]

Pearson J, Muller C, Frisco ML. Parental involvement, family structure, and adolescent sexual decision making. Sociological Perspectives. 2006; 49:67-90. doi: 10.1525/sop. 2006.49.1.67.

Phares, V. Fathers and developmental psychopathology. Wiley; New York: 1996.

Rai AA, Stanton B, Wu Y, Li X, Galbraith J, Cottrell L, et al. Relative influences of perceived parental monitoring and perceived peer involvement on adolescent risk behaviors: An analysis of six crosssectional data sets. Journal of Adolescent Health. 2003; 33:108-118. doi:10.1016/ S1054-139X(03)00179-4 DOI:dx.doi.org. [PubMed: 12890602]

Rodgers KB. Parenting processes related to sexual risk-taking behaviors of adolescent males and females. Journal of Marriage \& the Family. 1999; 61(1):99-109. doi:10.2307/353886.

Rollins, BC.; Thomas, D. Parental support, power, and control techniques in the socialization of children. In: Burr, WR.; Hill, R.; Nye, FI.; Reiss, IL., editors. Contemporary theories about the family. Vol. 1. Free Press; New York: 1979. p. 317-364.

Romer D, Stanton B, Galbraith J, Feigelman S, Black MM, Li X. Parental influence on adolescent sexual behavior in high-poverty settings. Archives of Pediatric Adolescent Medicine. 1999; 153:1055-1062.

Rose A, Koo HP, Bhaskar B, Anderson K, White G, Jenkins RR. The influence of primary caregivers on the sexual behavior of early adolescents. Journal of Adolescent Health. 2005; 37:135-144. doi: 10.1016/j.jadohealth.2005.02.009. [PubMed: 16026723]

Sameroff A. Transactional models in early social relations. Human Development. 1975; 18(1-2):6579. doi:10.1159/000271476.

Schinke SP, Fang L, Cole KCA. Substance use among early adolescent girls: Risk and protective factors. Journal of Adolescent Health. 2008; 43:191-194. doi: 10.1016/j.jadohealth.2007.12.014. [PubMed: 18639794]

Schulte MT, Ramo D, Brown S. Gender differences in factors influencing alcohol use and drinking progression among adolescents. Clinical Psychology Review. 2009; 29(6):535-547. doi:10.1016/ j.cpr.2009.06.003. [PubMed: 19592147]

Sieverding JA, Adler N, Witt S, Ellen J. The influence of parental monitoring adolescent sexual initiation. Archives of Pediatric Adolescent Medicine. 2005; 159:724-729. doi:10.1001/archpedi. 159.8.724.

Sieving RE, McNeely CS, Blum R. Maternal expectations, mother-child connectedness, \& adolescent sexual debut. Archives of Pediatric Adolescence Medicine. 2000; 154:809-816.

Silverberg, SB.; Small, SA. Parenting monitoring, family structure, and adolescent substance use; Paper presented at Meeting of the Society of Research on Child Development; Seattle, Washington. 1991;

Siqueira L, Diaz A. Fostering resilience in adolescent females. The Mount Sinai Journal of Medicine. 2004; 71(3):148-154.

Smith CA. Factors associated with early sexual activity among urban adolescents. Social Work. 1997; 42(4):334-346. [PubMed: 9228830]

Smith EA, Udry JR, Morris NM. Pubertal development and friends: A biosocial explanation of adolescent sexual behavior. Journal of Health and Social Behavior. 1985; 26:183-192. doi: 10.2307/2136751. [PubMed: 4067236] 
Sneed CD, Strachman A, Nguyen C, Morisky DE. The influence of parental monitoring and communication on adolescents sexual behavior and intentions. Vulnerable Children and Youth Studies. 2009; 4(1):27-47.

Stattin H, Kerr M. Parental monitoring: A reinterpretation. Child Development. 2000; 71:1072-1085. doi:10.1111/1467-8624.00210. [PubMed: 11016567]

Somerville LH, Jones RM, Casey BJ. A time of change: Behavioral and neural correlates of adolescent sensitivity to appetitive and aversive environmental cues. Brain and Cognition. 2010; 72(1):124133. doi:10.1016/j.bandc.2009.07.003. [PubMed: 19695759]

St. Lawrence JS, Brasfield TL, Jefferson KW, Alleyne E, O'Bannon RE, Shirley A III. Cognitivebehavioral intervention to reduce African American adolescents' risk for HIV infection. Journal of Consulting and Clinical Psychology. 1995; 63(2):221-237. doi:10.1037/0022-006X.63.2.221. [PubMed: 7751483]

Steinberg L. A social neuroscience perspective on adolescent risk-taking. Developmental Review. 2008; 28(1):78-106. doi:10.1016/j.dr.2007.08.002. [PubMed: 18509515]

Sterrett E, Jones DJ, Kincaid C. Psychosocial adjustment of low-income African American youth from single mother homes: The role of the youth-coparent relationship. Journal of Clinical Child and Adolescent Psychology. 2009; 38:427-438. doi: 10.1080/15374410902851663. [PubMed: 19437302]

Super, CM.; Harkness, S. The environment as culture in developmental research. In: Friedman, SL.; Wachs, BTD., editors. Measuring environment across the life span: Emerging methods and concepts. American Psychological Association; Washington, D.C.: 1999. p. 279-323.

Udry JR. Biological predispositions and social control in adolescent sexual behavior. American Sociological Review. 1988; 53:709-722. doi:10.2307/2095817.

Upchurch DM, Aneshensel CS, Sucoff CA, Levy-Storms L. Neighborhood and family contexts of adolescent sexual activity. Journal of Marriage and the Family. 1999; 61:920-933. doi: 10.2307/354013.

Webb JA, Bray JH, Getz JG, Adams G. Gender, perceived parental monitoring, and behavioral adjustment: influences on adolescent alcohol use. The American Journal of Orthopsychiatry. 2002; 72:392-400. doi:10.1037/0002-9432.72.3.392. [PubMed: 15792051]

Werner EE. Resilience in development. Current Directions in Psychological Science. 1995; 4:81-85. doi:10.1111/1467-8721.ep10772327.

Whitbeck LB, Yoder KA, Hoyt DR, Conger RD. Early sexual activity: A developmental study. Journal of Marriage and the Family. 1999; 61:934-946. doi: 10.2307/354014.

Wingood GM, DiClemente RJ. Application of the theory of gender and power to examine HIV related exposures, risk factors, and effective interventions for women. Health Education \& Behavior. 2000; 7:313-347.

Yang H, Stanton B, Li X, Cottrel L, Galbraith J, Kaljee L. Dynamic association between parental monitoring and communication and adolescent risk involvement among African-American adolescents. Journal of the National Medical Association. 2007; 99(5):517-524. [PubMed: 17534009]

Zimmer-Gembeck MJ, Helfand M. Ten years of longitudinal research on U.S. adolescent sexual behavior: Developmental correlates of sexual intercourse, and the importance of age, gender and ethnic background. Developmental Review. 2008; 28:153-224. doi:10.1016/j.dr.2007.06.001. 
そ

そ̊

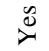

$\stackrel{0}{2}$

そ̊

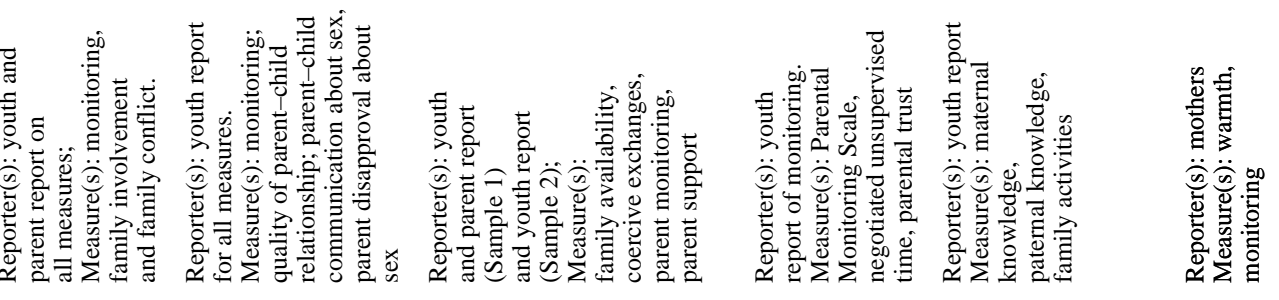

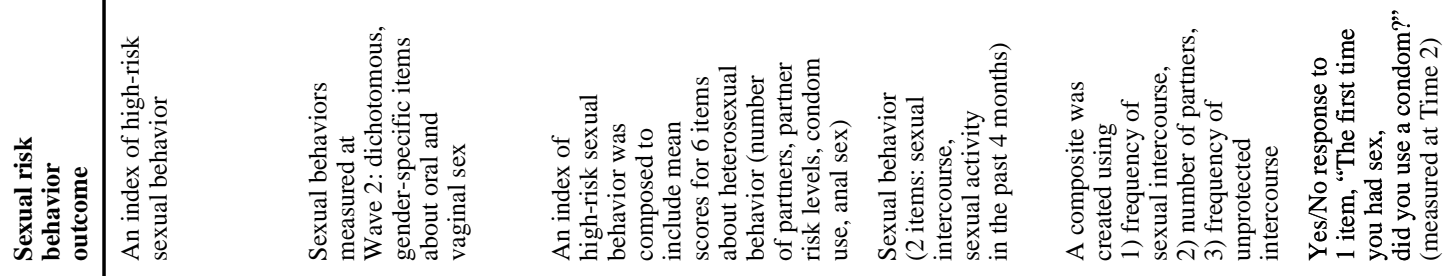

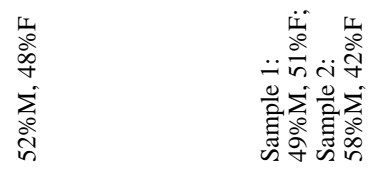

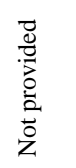

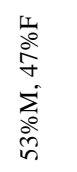

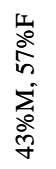




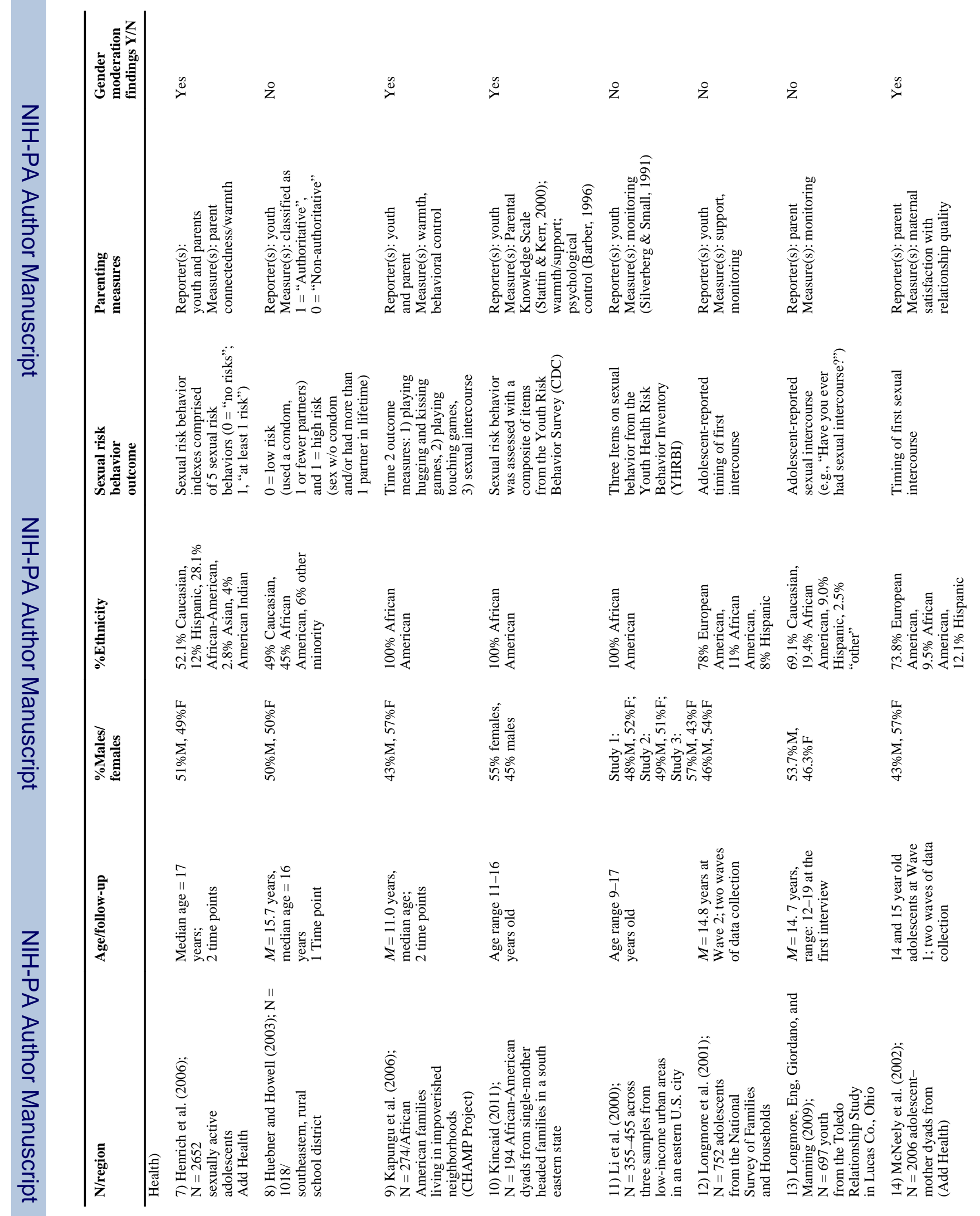




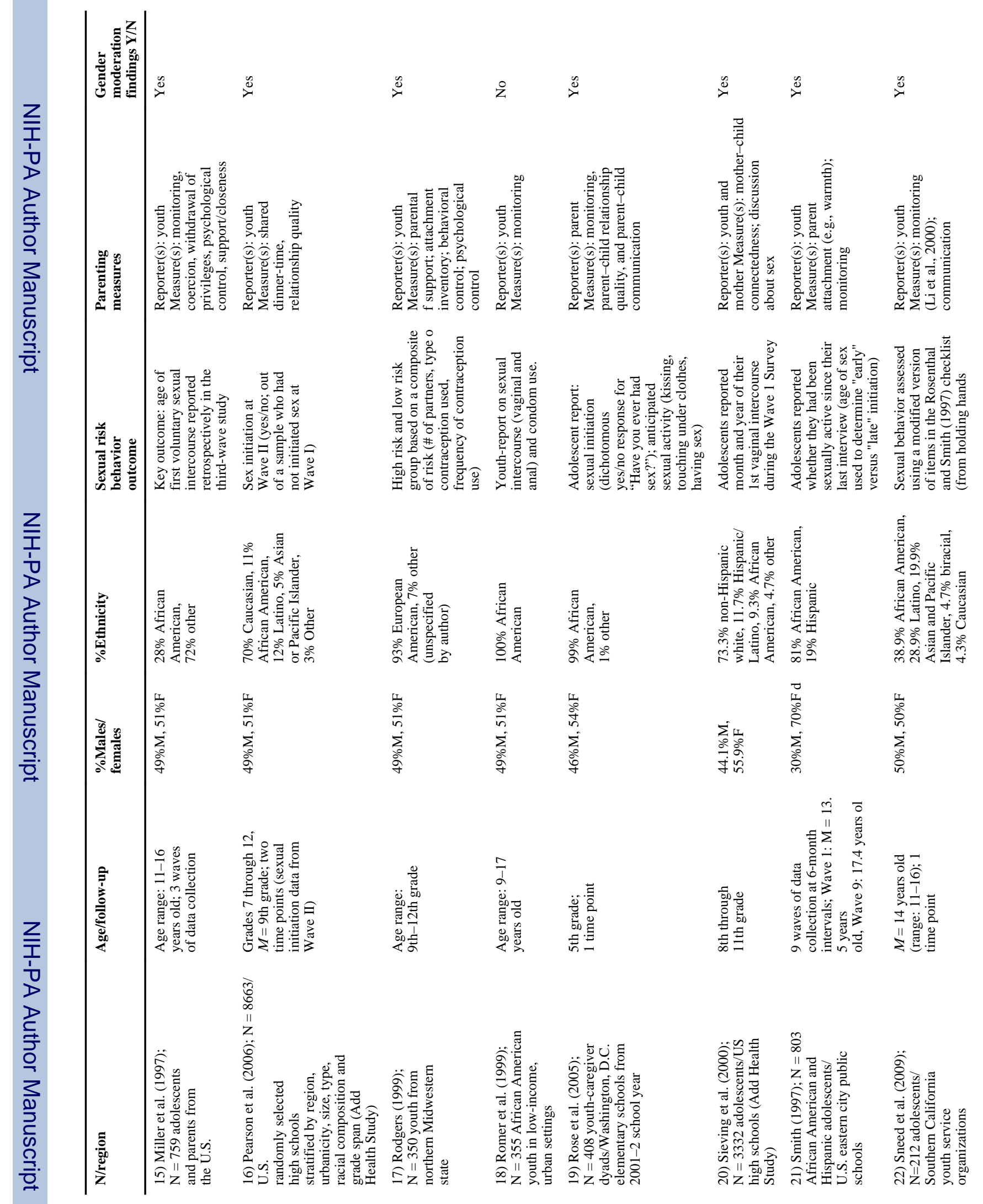


Kincaid et al.

Page 24

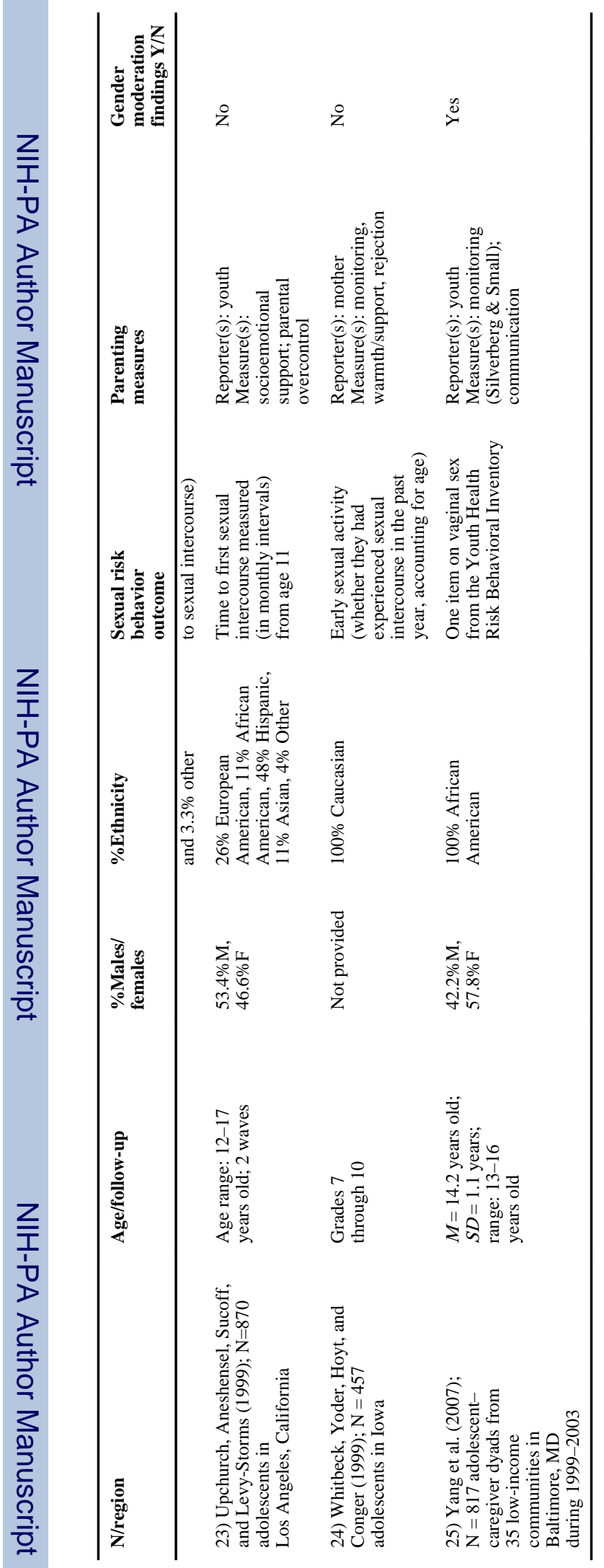

Clin Psychol Rev. Author manuscript; available in PMC 2013 June 27. 